\section{El dispositivo venezolano de sanidad y la incorporación de los médicos exiliados de la Guerra Civil española}

\section{The Venezuelan sanitation authority and the incorporation of physicians exiled from the Spanish Civil War}

Juan José Martin-Frechilla

Profesor titular da Universidad Central de Venezuela Apartado 76173 (El Marques)

Caracas 1070 A - Venezuela jumartin42@gmail.com

Recibido para publicación en abril 2007. Aprobado para publicación en noviembre 2007.
MARTIN-FRECHILLA, Juan José.

El dispositivo venezolano de sanidad y la incorporación de los médicos exilados de la Guerra Civil española. História, Ciencias, Saúde - Manguinhos, Rio de Janeiro, v.15, n.2, p.519-541, abr.-jun. 2008.

Resumen

En 1914, mientras España establecía acuerdos para modernizar su estructura científica y sanitaria, al hilo del panamericanismo y de los controles por la apertura del Canal de Panamá, Venezuela comenzó a estructurar un dispositivo sanitario ajustado a pautas internacionales, auspiciado, desde 1913, por la Fundación Rockefeller. En 1931, la Segunda República aceleró en España el envío de becarios a Estados Unidos y creó un sistema de salud pública bajo el modelo administrativo de unidades sanitarias y unidades técnicas de investigación y control propugnado por la Fundación. La Guerra Civil interrumpió ese proceso y Venezuela aprovechó el momento para contratar a médicos y enfermeras exiliados y los incorporó al nuevo Ministerio de Sanidad y Asistencia Social creado 1936.

Palabras clave: salud pública; Venezuela; exilio republicano; Fundación Rockfeller; Guerra Civil española.

\section{Abstract}

In 1914, while Spain was making agreements to modernize its scientific and sanitary structure, Venezuela started to structure a sanitation authority following international models, in line with Pan Americanism and the controls for the opening of the Panama Canal, for which is received sponsorship from the Rockefeller Foundation as of 1913. In 1931, the Second Spanish Republic sent ever greater numbers of scholars to study in the United States and established a public health system along the lines of the administrative models for sanitation and technical units for investigation and control as proposed by the Foundation. The Spanish Civil War interrupted this process and Venezuela seized the moment to hire the exiled doctors and nurses and incorporate them into its new Ministry for Sanitation and Social Welfare, created in 1936.

Keywords: public health; Venezuela; exiles from the Republic; Rockfeller Foundation; Spanish Civil War. 
$\mathrm{E}$ 1 exilio, además de ser un asunto individual y colectivo, un proceso político y social de consecuencias económicas, es un acontecimiento que emparenta - a dos bandas con historias sociales particulares de la educación, de la ciencia, de la tecnología o de la salud pública, por ejemplo. Dos bandas que reconocen la necesaria articulación de éstas a las respectivas historias nacionales, la del país que expulsa y la del que recibe, ello a fin de poder reconstruir la transferencia de conocimientos, sus características, su asiento. De modo que la resonancia de lo que médicos y enfermeras trajeron como equipaje intelectual saberes, estructuras, modelos - debe calibrarse a partir del desarrollo doméstico de esos rubros. En el ámbito de la medicina y de la salud pública - modelos y estructuras para su organización - encontramos problemas y soluciones equiparables con el momento de la conexión entre los profesionales exiliados y los colegas venezolanos. El significativo número de médicos exiliados, y también de enfermeras, que llegaron contratados desde 1936 por la administración pública venezolana nos informa, por una parte, de las posibilidades fiscales del país para resolver sus necesidades organizativas, pero, también, de que los médicos venezolanos estaban en capacidad de establecer los parámetros para una inmigración selectiva que atrajese con éxito a algunos colegas españoles, con los cuales habían establecido, en las primeras décadas del siglo XX, vínculos profesionales y académicos y que ahora reemplazaron como portavoces de las posibilidades laborales de Venezuela.

\section{La sanidad nacional hasta 1936: primeras transferencias}

En el último cuarto del siglo XIX, el segundo impulso del proyecto nacional de modernización del país - si contamos como primero el emprendido al calor de las reformas borbónicas al final del período colonial - estuvo orientado a la construcción de ferrocarriles, edificios públicos e infraestructuras, a la implantación de códigos, censos y publicaciones oficiales, a la creación de las primeras instituciones públicas modernas; todo ello en clara señal positivista orientada a confirmar la 'desespañolización' - como la bautizó Leopoldo Zea - que marcaría los primeros ensayos de nación independiente en un proceso similar al seguido por los otros países latinoamericanos. Se trató, bajo la férula de Antonio Guzmán Blanco, de un amplio programa de intervención del Estado central. Con desigual eficacia, el Ministerio de Fomento desde 1863 y, sobre todo, el Ministerio de Obras Públicas desde 1874, fueron los responsables de adelantarlo; de este último se desprendería en 1881 el Ministerio de Instrucción Pública para darle a la educación un estatuto que trascendiese a las edificaciones. Desde los primeros años de vida nacional independiente, el Ministerio de Relaciones Interiores fue matriz desde la cual se fueron originando estos ministerios y los posteriores de Justicia, Trabajo, Sanidad y Asistencia Social, Agricultura y Cría, Transporte y Comunicaciones, Energía y Minas, y ello hasta bien entrado el siglo XX. Sin embargo, a pesar de que la salubridad pública, los cementerios, los hospitales, los lazaretos o la vacunación estuvieron nominalmente a cargo de este ministerio hasta las primeras décadas del siglo XX, lo cierto es que como herencia colonial el saneamiento urbano, la higiene y los servicios sanitarios siguieron siendo, aun en su precariedad, competencia municipal.

Las experticias profesionales para afrontar estos asuntos - medicina e ingeniería - tuvieron asiento formativo en la Universidad de Caracas, tardíamente fundada en 1721 si nos 
atenemos al resto de las universidades americanas. Así, la cátedra de medicina tuvo que esperar a 1763 y a 1777, cuando se creó el Protomedicato, para el cuidado de la salud pública y el control profesional de grados y títulos. Los estudios de ingeniería por su parte, deslindados de la impronta militar, pasaron a la Universidad al final del siglo XIX. Sin embargo, mientras las obras públicas fueron un detonante de excepción para el desarrollo de la ingeniería en el país - en 1861 fue creado el Colegio de Ingenieros de Venezuela como organismo asesor del estado - la salud pública no corrió con igual suerte.

La exposición de motivos y los artículos de una resolución del Ministerio de Instrucción Pública en 1889 ayudan a dibujar el interés en el campo de la medicina:

Observándose que los estudios médicos en Venezuela se resienten de lamentable deficiencia en el campo objetivo de la experimentación, ora por falta de clínicas especiales y de museos y gabinetes científicos donde pueda hacerse ejercicio práctico de las teorías de la facultad, ora por falta de profesores especialistas en determinados ramos esencialmente esperimentales [sic] que han obtenido hoy notable perfeccionamiento, y en los que el progreso moderno ha encontrado la base de nuevos sistemas y sorprendido el secreto de nuevas medicamentaciones [sic] (Recopilación..., 1891, p.275). ${ }^{1}$

Por ello se creó una beca para estudiar microscopia, bacteriología, histología normal y patológica y fisiología experimental en París. Durante sus estudios, el médico seleccionado se comprometió a trasmitir a la Facultad de Ciencias Médicas las noticias y observaciones de interés, además de los informes trimestrales sobre sus avances académicos y, a su regreso, a crear en el Hospital Vargas - entonces en construcción e inaugurado en 1891 - "un gabinete fisiológico" y a dictar en la Universidad Central "las materias susodichas" (Vargas Arenas, 1991, p.44). ${ }^{2}$ El resultado efectivo de estas intenciones quedó plasmado en la creación, bajo la influencia de la escuela francesa de medicina, de numerosas cátedras a partir de 1895: bacteriología, parasitología e histología en la Universidad Central de Venezuela (UCV) mientras que el Hospital Vargas acogía las de clínica médica y anatomía patológica, clínica quirúrgica y clínica de obstetricia y ginecología. (Leal, 1981, p.218). El mismo año se hizo pública una campaña de suscripciones a fin de crear el Instituto Pasteur de Caracas para el estudio de la microbiología y sus aplicaciones, iniciativa privada que en 1897 sería acogida por el ejecutivo bajo forma de decreto (Rodríguez Lemoine, 1999, p.232ss.).

Pero si la formación académica pasaba por estos trances, las edificaciones sanitarias estuvieron marcadas por la precariedad hasta la inauguración en 1891 del Hospital Vargas. Un reporte escrito al calor de este acontecimiento señalaba que los hospitales eran "casas inmundas, en donde se hacinaban los infelices que no tenían donde morir" (Villanueva, 1885, p.CCXXVIII). Renovación de los estudios de medicina y nuevas edificaciones hospitalarias en las cuales desarrollar una clínica moderna llevó al historiador Ricardo Archila a señalar este momento como el del "renacimiento de la medicina en Venezuela" (Archila, 1952, p.38). Luís Razetti como figura esencial y junto a él toda una generación de médicos serían los responsables de la constitución del dispositivo de salud publica venezolano. Médicos nacidos en la segunda mitad del siglo XIX, graduados en la UCV alrededor de su última década y con estudios de especialización en Europa - Francia en primer lugar, pero también enfermedades tropicales en Inglaterra y Alemania - , irán apareciendo como responsables de oficinas, laboratorios, ministerios, a la vez que algunos llegarían a ser designados rectores de la Universidad. 
Este renacer de la medicina no estuvo al margen de la nueva situación política del país cuando la preterida región andina productora fundamental del café para la exportación le pasó factura al poder central instalándose en Caracas, luego de una revolución encabezada por Cipriano Castro con Juan Vicente Gómez como segundo al mando. Durante los dos primeros gobiernos 'andinos' - Castro (1899-1908) y Gómez (1908-1935) ${ }^{3}$ - se impulsaron varias iniciativas - leyes, reglamentos y organismos - para que la higiene y la salud pública se articulasen técnicamente con la construcción urbana de edificaciones y obras civiles. Así fueron creadas las primeras instituciones: la Dirección de Higiene y Estadística Demográfica del Distrito Federal ${ }^{4}$ de 1899, a nivel local; la Comisión de Higiene Pública de 1909, - luego Dirección de Higiene y Salubridad Pública en 1910 - del Ministerio de Relaciones Interiores; y, finalmente, la Oficina de Sanidad Nacional (OSN) de 1911. En ellas se adoptaron normas y establecieron competencias con el fin de dar cumplimiento al saneamiento urbano que requería la modernización de los acueductos, la construcción de las redes de cloacas y la pavimentación de las calles.

La intervención pública en el control sanitario y el saneamiento de las ciudades tuvo difusión continental al calor de la Primera Conferencia Internacional Americana de 1889 que culminó con la creación de la Unión Internacional de Repúblicas Americanas. ${ }^{5}$ Pero los antecedentes en la cuestión sanitaria se remontan a 1881, cuando los Estados Unidos, ante la extensión de virulentos brotes de fiebre amarilla, solicitó que la $5^{\text {a }}$ Conferencia Sanitaria Internacional sesionase en Washington. ${ }^{6}$ La II Conferencia Internacional de Estados Americanos celebrada en México - 22 de octubre 1901 al 22 de enero 1902 - convocó para finales del mismo año la I Convención Sanitaria Internacional de las Repúblicas Americanas que posteriormente se denominaría Conferencia Sanitaria Panamericana. ${ }^{7}$ A esa reunión asistirían los representantes de las oficinas de sanidad de los países americanos. El papel difusor y promotor que en el campo de la medicina, la sanidad y la higiene tuvieron estas reuniones se reflejará en las disposiciones y acuerdos sobre medidas y legislación; condiciones sanitarias de los puertos; estadísticas de población; saneamiento de ciudades, especialmente los puertos para la protección del embarque en puertos infectados; medidas sanitarias en relación a la fiebre amarilla, la peste bubónica, la malaria y las enfermedades venéreas.

La articulación entre medicina e ingeniería alrededor de las disposiciones e instituciones a nivel local y nacional quedó claramente establecida en las resoluciones del $1^{\circ}$ Congreso Venezolano de Medicina celebrado en 1911 bajo la égida esencial de Luís Razetti. Ellas incorporaron los informes, las recomendaciones, las medidas y las leyes que desde la conferencia de Washington se estaban difundiendo como perentorias en todos nuestros países (Razetti, 1911). La primera resolución del congreso estableció la necesidad de crear "un cuerpo supremo de salubridad que dicte el Código Nacional de Higiene y Salubridad"8 junto a laboratorios de bacteriología y parasitología en las capitales de los Estados - la denominación en Venezuela para las provincias - para el estudio del paludismo y demás patologías tropicales "de acuerdo a las exigencias de la ciencia experimental". A la vez propuso como obligatoria en la enseñanza primaria y normal la "higiene profiláctica general e individual" y se solicitaron medidas concretas para la promoción de campañas antipalúdicas (Razetti, 1962, p.107). Todos estos aspectos fueron en buena parte resultado 
de la discusión de la ponencia presentada por Francisco Antonio Rísquez y Carlos Manuel Velásquez, titulada "El paludismo en Venezuela".9

La Comisión de Higiene Pública del Ministerio de Relaciones Interiores, cuyo secretario era Luís Razetti, incorporó entre sus miembros, además de los médicos, a un ingeniero y a un abogado debido a los alcances de los problemas sanitarios que debía afrontar: saneamiento de puertos, propagación de la vacuna antivariólica, abasto de agua, aseo urbano, cloacas y pavimentos e inspección técnica de alimentos y bebidas. Sin embargo, la Comisión fue substituida por el Consejo Superior de Higiene y Salubridad Pública con representación institucional de los catedráticos de higiene, física y química biológica, fisiología y bacteriología de la UCV, los presidentes de los colegios profesionales - ingenieros y abogados -, los médicos directores del hospital militar, del manicomio y la leprosería, además del Inspector General de Hospitales. Mientras el Consejo establecía la orientación político-administrativa general, se creó un brazo ejecutivo con la Dirección de Higiene y Salubridad Públicas el mismo año 1910. Este ajuste progresivo a las pautas sanitarias internacionales culminará con la creación en 1911 de la Oficina de Sanidad Nacional y la promulgación, un año después, de una nueva Ley de Sanidad Nacional. Las competencias de la Oficina eran amplias. Incluían la profilaxis (epidemiología, vacunación, desinfección, desratización, luchas contra moscas y mosquitos, drenajes, hospitalización); la inspección de farmacias y profesiones; los certificados de salud; los servicios de puericultura, antituberculoso, antivenéreo; la ingeniería sanitaria; los laboratorios de bacteriología y parasitología, química, aguas; la inspección de casas, alimentos, aseo urbano. Quedaron de este modo cumplidas, en muy buena parte, las recomendaciones del congreso de medicina.

También en 1911, para conmemorar los cien años de la independencia, se reunió en Caracas otro congreso esencial: el $1^{\circ}$ Congreso de Municipalidades de Venezuela. Entre sus organizadores estuvo Luís Razetti, a cargo de la Comisión de Sanidad y Régimen Hospitalario. En este congreso quedó establecida la necesidad de que todos los municipios del país tuviesen ordenanzas que dieran cuerpo orgánico a competencias, disposiciones y organismos de control y sanción a nivel urbano (Congreso..., 1983). Para ese momento sólo el Concejo Municipal de Caracas había aprobado, en 1910, una ordenanza de policía urbana y rural en cuyo capítulo "De la arquitectura civil" se encontraban, junto a las reglas para construir y demoler y para solicitar los permisos respectivos, una normativa en higiene y salubridad de acuerdo con los distintos tipos de edificios públicos e infraestructura urbana (Gaceta Municipal del Distrito Federal, 1910, p.478).

Los vínculos entre el problema del abastecimiento de agua en Caracas y el decrecimiento de su población fue alertado por Razetti en su ponencia "Caracas se despuebla" ante el congreso de municipalidades de 1911. Las cifras "traducen un deplorable estado sanitario" y frases como es necesario "un plan racional de saneamiento" - hicieron que el Servicio de Ingeniería Sanitaria tuviese un papel esencial en el desarrollo institucional de la Oficina de Sanidad Nacional. Sin embargo, las competencias entre el Ministerio de Obras Públicas, como responsable de la construcción y dirección de las obras, y su planificación y vigilancia, a cargo de la Dirección de Sanidad Nacional (DSN), denominada así desde 1919, no aligeraron los alcances y los procedimientos. Así, en 1926, llegó a Caracas Thorndike Saville, 
en calidad de jefe de la Misión de Ingeniería Sanitaria enviado por acuerdo firmado entre la Dirección de Sanidad Nacional y la Fundación Rockefeller, que como veremos ya se encontraba trabajando en el país en el campo de las enfermedades contagiosas. Saville, quien era miembro de la Junta Internacional de Salud de la Fundación y profesor de la Universidad de North Carolina (EEUU), se encargó durante dos años del Departamento de Ingeniería Sanitaria con el objetivo de reorganizarlo y, sobre todo, de estudiar el problema del abastecimiento de agua de la capital. Para esta última tarea, Saville estuvo acompañado de otro ingeniero sanitario - Franck M. Bell - a la sazón miembro del Departamento de Conservación y Fomento del Estado de North Carolina (Archila, 1956, p.43-44).

Sobre los conflictos de competencia entre sanidad y obras públicas algo se avanzó en la reforma legal aprobada en 1927. El Decreto Orgánico de Sanidad Nacional rescataba todas las funciones relativas a la ingeniería sanitaria para el nuevo servicio. Sin embargo, estas mejoras administrativas tropezaron con el Ministerio y en 1927 quedaron suspendidas tanto la presencia de los asesores de la Fundación como la autonomía relativa del Servicio de Ingeniería Sanitaria en los asuntos de su competencia. En relación al abastecimiento de agua, Thorndike Saville entregó en 1927 un completo informe sobre los factores que influían en el abastecimiento de agua de la capital (Saville, 1933). Apoyado en buena parte en datos y proposiciones previas, elaboradas por ingenieros venezolanos en las que se habían evaluado las distintas posibilidades para la producción de agua potable, Saville se inclinó por una combinación de pozos y represa recomendando la cloración y el filtrado para eliminar las bacterias y turbieza. Su relato de las características del sistema de distribución, del suministro de agua a las casas, solo dos o tres horas al día, y la necesidad de estanques de almacenamiento, las dificultades de un cobro equitativo del agua al pagarse el servicio por una cantidad fija anual de "derecho de agua", independiente de la presión y en consecuencia de la cantidad de agua suministrada, constituyen un descarnado informe sobre nuestras precariedades. Sin embargo, Saville finaliza dándole una visión optimista "a los ingenieros norteamericanos" a quienes se le ofrecerán en el futuro "muchas oportunidades de trabajar en la elaboración de proyectos y en la construcción de obras modernas de abastecimiento de agua" en las ciudades venezolanas. A pesar de que estas primeras asesorías de parte de la Fundación Rockefeller se interrumpieron y sus resultados tardaron en asentarse, en 1928 se inició un modesto programa de becas para que profesionales graduados en Venezuela estudiasen ingeniería sanitaria en la Universidad de North Carolina.

La otra vertiente de los acuerdos con la Fundación Rockefeller giró alrededor de las enfermedades contagiosas. A consecuencia de la propagación de la fiebre amarilla por la apertura del canal de Panamá, la Fundación creó en 1916 una Comisión Especial de Fiebre Amarilla que visitó los puertos más importantes de la región tropical de América Latina, entre ellos los venezolanos La Guaira, Puerto Cabello y Maracaibo. Si bien la Primera Guerra Mundial puso en cuarentena las campañas que se propusieron, la visita de William C. Gorgas, Henry Rose Carter y Juan Guiteras Gener no constató focos de infección aunque recomendaron que se mantuviera bajo observación nuestra costa caribeña (Guiteras, 1917) En 1924, la Fundación envió otros dos expertos que recorrieron todo el país y confirmaron el control de la fiebre amarilla y la capacidad profiláctica de los servicios establecidos en el país. 
La malaria y la anquilostomiasis fueron las otras enfermedades alrededor de las cuales la Fundación Rockefeller estableció convenios con el país y envió misiones técnicas. Es así como en 1926, mientras Thorndike Saville se incorporaba a la Dirección de Sanidad Nacional, llegaba a Venezuela el doctor Rolla B. Hill - luego del convenio establecido entre el gobierno venezolano y la División de Sanidad Internacional de la Fundación - a fin de profundizar la lucha contra ambas enfermedades. El centro piloto quedó establecido en la ciudad de Maracay, en los valles centrales del país. Con los conocimientos acumulados sobre la anquilostomiasis en Venezuela - Rafael Rangel ${ }^{10}$ había identificado en 1903 el Alonecator americanus como el parásito transmisor - y con la colaboración de los médicos venezolanos de la DSN, Hill emprendió entre febrero de 1927 y marzo de 1928 las encuestas relativas a ambas enfermedades. Los exámenes practicados para el estudio de la anquilostomiasis dieron resultados positivos en un $70 \%$ de casos en los valles centrales. En junio de 1928, Hill presentó a la Dirección de Sanidad Nacional un proyecto de lucha contra la enfermedad en cuatro fases: prevención - construcción de letrinas -, curación, educación y conservación (Ochoa Molina, 2002).

En relación a la malaria, Hill y los médicos venezolanos A. Levy Romero y Elías L. Benarroch publicaron en 1928 "la primera encuesta malariomérica de reconocimiento" en la cual identificaron a los anofeles transmisores en las regiones del país (Archila, 1956, t.1, p.180-186; Hill, Benarroch, 1940). A fin de evaluar in situ los resultados de los estudios y las políticas diseñadas para iniciar la campaña antimalárica, se sumó a la misión de la Fundación Rockefeller, durante tres meses, el doctor Franck M. Root, entomólogo de la Universidad de Johns Hopkins. A Hill y Benarroch los sucedieron, en 1929, John E. Elmendorf y Roberto Villalobos Ferrer. La disyuntiva sobre si fue el gobierno venezolano quien suspendió temporalmente la cooperación con la Fundación Rockfeller en 1932 o, si por el contrario, fue ésta la que lo hizo en razón a "las condiciones políticas desfavorables" (Vessuri, 1999, p.320), es un asunto pendiente a investigar. ${ }^{11}$ Si rescatamos la afirmación de que la llegada de la Fundación a Venezuela "coincide con la intensificación de la explotación petrolera en la cual el grupo Rockefeller tuvo un participación importante" (García, 1981, p.108), nos inclinamos más hacia la hipótesis de que pudo ser Venezuela la que suspendió la cooperación. Ello hace suponer, tanto por los sucesos estudiantiles de 1928 que potenciaron una aún incipiente oposición al régimen como por los acontecimientos de la situación internacional del momento en nuestro entorno geográfico y el síndrome del bloqueo y la intervención extranjera con el cual Juan Vicente Gómez llegó al poder en 1908, año en que los Estados Unidos intervinieron la primera de cuatro veces en Panamá. ${ }^{12}$ En todo caso, en 1932 culminó con la Fundación Rockefeller - enfermedades contagiosas e ingeniería sanitaria - una primera transferencia que sería retomada luego de la muerte natural de Juan Vicente Gómez. En ese momento otras se cruzarían con ella.

\section{Los hilos de la transferencia en torno a 1936}

En España, los primeros contactos con la Fundación Rockfeller se iniciaron en 1911, cuando su Junta Internacional de Salud envió a Madrid un cuestionario sobre la anquilostomiasis en coincidencia con similares iniciativas en América Latina: la anemia 
en el medio rural americano se correspondía con la anemia de los mineros españoles (Rodríguez Ocaña, Bernabeu-Mestre, Barona Vilar, 1998). Luego de estos primeros acuerdos sobre la anquilostomiasis, en 1917, el asunto de las cuarentenas marítimas y las condiciones sanitarias de los puertos españoles también interesaron a la Fundación. Sin embargo, a pesar de otros contactos, no sería hasta después de finalizada la Primera Guerra Mundial que la Rockefeller estructuró su presencia en Europa en el terreno de la investigación y la educación científica como "remedios a largo plazo de la pobreza" (p.531). El acuerdo de cooperación fue firmado con España en 1919. Entre 1921 y 1922 los enviados de la Fundación recorrieron la península en misión científica a fin de precisar la estrategia de sus actuaciones. Al igual que en Venezuela, la base de apoyo local fue esencial para su trabajo; sin embargo, a pesar de la presencia de destacados sanitaristas - Sadí de Buen en primer lugar - y de una cierta estructura sanitaria, la misión observó una notable carencia de personal entrenado, médicos e inspectores en primer lugar. Mientras que por otra parte, en Andalucía, destacaron el problema de la higiene urbana, de la dotación, la continuidad y la calidad del suministro de agua potable, al igual que la precariedad de las redes de recolección de las aguas servidas. Sin embargo, los términos del acuerdo de cooperación se centraron en la formación de recursos humanos por medio de un programa de becas y en el control de tres de las enfermedades endémicas más importantes de España: tuberculosis, anquilostomiasis y paludismo.

De este primer acuerdo quedó un fortalecido programa de becarios en el exterior - casi cuarenta entre bioquímica, medicina, enfermería, botánica y sobre todo salud pública - y la creación e instalación de un laboratorio de física y química en Madrid. Con el triunfo electoral de 1931 y la implantación de la Segunda República, los vínculos con la Fundación se reforzaron. Marcelino Pascua (1897-1977), desde su designación como Director General de Sanidad ${ }^{13}$, emprendió una reforma del sistema de sanidad nacional que incluyó la creación de comisiones permanentes de investigaciones sanitarias, secciones de ingeniería y arquitectura sanitaria, higiene infantil, higiene social y difusión, así como una entonces novedosa sección de psiquiatría e higiene mental (Bernabeu-Mestre, 2000). Con Pascua trabajaron algunos de los médicos que se exiliarían posteriormente en Venezuela: José Sánchez Covisa, Jesús Sahagún y Santiago Ruesta, entre otros. La Guerra Civil y su desenlace permitieron que estos temas y esquemas organizativos se insertaran con fluidez en la organización de la sanidad nacional venezolana emprendida a la muerte, en diciembre de 1935, de Juan Vicente Gómez.

Para ese momento Venezuela había dejado de ser un país preterido. Al finalizar la Gran Guerra comenzó a hacerse notar, fuimos por primera vez visibles. Las concesiones que otorgábamos, su transferencia a las empresas petroleras para la exploración y su explotación despertaron rápidamente el interés por la nueva 'tierra de gracia'. Los negocios del capital internacional prosperaron a un ritmo vertiginoso ante la exitosa localización de las reservas y su no menos impresionante cuantificación. Al interior, el negociado de las concesiones petroleras por parte de los testaferros nacionales adosados al régimen creó nuevas fortunas. Pero la abundancia era tal que terminó por drenar hacia territorios cada vez más amplios de la sociedad. Tuvimos, porque lo pudimos pagar, una nueva clase media civil y militar próspera al calor de las instituciones y las necesidades que la trama del negocio petrolero iba requiriendo en la administración pública y en los servicios privados. En menos de 
cincuenta años, las inversiones en obras públicas, educación y salud crecieron para reflejarse con claridad en el aumento de la esperanza de vida del venezolano y en la inversión de la relación entre la población rural y la urbana como resultado de las migraciones internas. Nos cambió socialmente el talante, pasamos de pobres a ricos por un golpe de fortuna. Aunque no corresponde aquí evaluar la digestión de este acontecimiento, no es posible dejar de resaltarlo para que permanezca como fondo referencial de las distintas iniciativas en relación a la incorporación de los médicos exiliados republicanos, tanto a la academia como al dispositivo de salud pública venezolano (Martín Frechilla, 2005).

Desordenado a veces, pero consciente de la necesidad de planificar el gasto de los crecientes recursos fiscales, el estado venezolano fue empujando todos los registros del proyecto nacional de modernización que, a partir de 1936, recibió un envite singular en su estructura y alcances. Juan Vicente Gómez había gobernado hasta 1930, con siete ministerios: Relaciones Interiores y Exteriores, Hacienda, Guerra y Marina, Fomento, Obras Públicas e Instrucción Pública, a los cuales agregó ese año el de Salubridad y Agricultura y Cría, con competencias provenientes de Relaciones Interiores. Se estaba de esta forma cumpliendo con una de las recomendaciones de la $8^{\text {a }}$ Conferencia Sanitaria Panamericana celebrada en 1927. En los primeros seis meses de la transición democrática, el gobierno venezolano aprobó, en julio de 1936, una nueva constitución. Antes había concertado con la oposición antigomecista. A raíz de violentos incidentes de calle, el denominado Programa de Febrero ${ }^{14}$, en marzo de 1936, se creó el Ministerio de Sanidad y Asistencia Social (MSAS), entre otros organismos del sector público. La rapidez con la cual se pudo elaborar una constitución y negociar el programa de gobierno que requería el nuevo presidente en términos de credibilidad política y económica - amén de estabilidad - solo es posible explicarla por los aportes de un grupo de intelectuales que podría ser denominado el Grupo de Ginebra, ya que había sido en la Liga de las Naciones donde tuvieron la oportunidad de ir madurando durante el período de entreguerras, y para cuando la realidad política venezolana fuese propicia, un nuevo proyecto de modernización enraizado en las bases del primer gomecismo. ${ }^{15}$

El médico venezolano Enrique Tejera (1899-1980), que había sido designado ministro de Salubridad y de Agricultura y Cría el 11 de febrero de 1936, puso en funcionamiento, en apenas quince días, la estructura organizativa de la salud pública, evidentemente madurada desde hacía unos años, desde la época en la que estuvo a cargo del Laboratorio de Microbiología de la Oficina de Sanidad Nacional. Se trató de un sistema nacional de salud pública, concebido bajo el modelo administrativo de unidades sanitarias y de nuevas unidades técnicas de investigación y control, como lo propugnaba exitosamente en el ámbito internacional la Fundación Rockefeller, que incorporaba también las discusiones, estructuras y recomendaciones desarrolladas dentro de la Comisión de Malaria de la Liga de las Naciones desde 1924. Los contactos para la cooperación de la Fundación Rockefeller fueron reanudados por Enrique Tejera al llegar al Ministerio. Si bien Tejera lo dejaría en julio de 1936 para encargarse de la embajada de Venezuela en Bélgica, los acuerdos se formalizaron en el campo de la malariología con médicos que habían trabajado con anterioridad junto a los asesores de la Fundación y también con el inicio de un programa de becas en universidades norteamericanas. 
Justamente un desencuentro con relación al campo de la malaria, como reflejo de la división de criterios entre las dos escuelas del momento - mitigar o erradicar -, en cuanto a "la pertinencia o no de conocer más sobre el paludismo antes de enfrentar su control o su erradicación", fue lo que ocasionó la renuncia de Enrique Tejera (Gutiérrez, 1998, p.7, 8). El tema no era en modo ajeno a la comunidad médica nacional, no sólo por las actuaciones de la Fundación Rockefeller en ese campo, sino por iniciativas como la impulsada en 1931 por el sector público al dedicar la II Conferencia Sanitaria Nacional al "análisis y estudio del paludismo en Venezuela". En ese evento fueron presentados los resultados de un encuesta "en cuya elaboración y ejecución intervino un grupo de técnicos venezolanos, entre ellos Arnoldo Gabaldón"; vinieron después las comisiones de la Campaña Antipalúdica, el Plan de Lucha Antipalúdica y la creación de un departamento especial de malariología, sin que estas iniciativas se cristalizaran "en la constitución de un grupo dedicado a estudiar de forma sistemática y permanente todos los aspectos del problema malario nacional" (p.13). En todo caso, cuando en mayo de 1936 el Congreso Nacional discutía el proyecto de Ley de Defensa Contra el Paludismo, Tejera criticó severamente el proyecto en apoyo a la dura oposición manifestada públicamente por los médicos higienistas venezolanos "no satisfechos del plan defensivo" que establecía. En junio fue aprobada por el congreso la ley - que no era sino la transcripción de la ley argentina de 1907 con algunos artículos de su reglamento de 1911. Pero antes de tener que firmar como miembro del gabinete ejecutivo el ejecútese a la ley, Tejera renunció (López Ramírez, 1987, p.50-53). Esta ausencia de consenso oponía a los que creían que en el país no se habían realizado estudios sobre malaria "con una metodología científica". Si bien se había producido "una información importante para adaptar una tecnología foránea a la solución del problema palúdico del país", otros destacaban que se había realizado "investigación científica siguiendo un modelo de hacer ciencia desarrollado en países como los Estados Unidos" (Gutiérrez, 1998, p.15).

En julio de 1936 también se aprobó una nueva Ley de Inmigración y Colonización como marco para una inmigración cualitativamente importante. Era la muestra de que los más variados campos de actuación de un sector público en expansión requerían de profesionales bien calificados. En el caso del Ministerio de Sanidad y Asistencia Social, la inestabilidad administrativa de la transición democrática no afectó en modo alguno la dirección de las políticas de salud pública emprendidas desde 1936. Tejera y los que le sucedieron hasta finales de la década de los cincuenta, como ministros y directores de las distintas divisiones e institutos del campo de la salud pública, eran médicos e investigadores - buena parte de ellos en el campo de las enfermedades tropicales - que habían realizado estudios de postgrado en el extranjero, pertenecían a sociedades científicas y estaban vinculados, por la vía de los congresos internacionales y las revistas de sus respectivas especialidades, a los debates de la comunidad científica sobre la necesidad de crear infraestructuras para la investigación y la docencia enmarcadas en un dispositivo de atención, educación, prevención y control sanitario de la población (Rodríguez Lemoine, 1996).

Como muestra de que Tejera se encontraba entre los que consideraban insuficiente la investigación médica en el país, desde 1939, cuando se reincorporó al ejecutivo como ministro de Educación Nacional, desplegó nuevas iniciativas que apuntaban a sacar a la universidad 
venezolana del largo letargo en el cual había estado sumergida durante la dictadura gomecista, en particular con el cierre de la UCV por más de 12 años. Así, Tejera puso en práctica una inmigración selectiva de alto nivel en el campo de la medicina, mientras el MSAS contrataba por su parte a un buen número de médicos exiliados para el desarrollo de sus políticas. En algunos casos, la docencia universitaria en cátedras de pre y postgrado quedaba estipulada como parte de su dedicación en los contratos de quienes habían sido catedráticos en las universidades españolas y poseían una formación más especializada.. En estos últimos casos, la Facultad de Ciencias Médicas de la UCV comenzó a compartir con el MSAS algunas competencias una vez que quedaron reglamentados, por ejemplo, los cursos de médicos higienistas y la UCV asumió, desde 1942, el otorgamiento del título y el diploma profesional correspondiente. Una parte importante de estos cursos estuvo a cargo de los médicos exiliados José Sánchez Covisa (venereología), Santiago Ruesta (administración sanitaria), Luis Bilbao (bacteriología) y José Ortega Durán (higiene materno-infantil). En cuanto a las cátedras en la UCV, el caso más significativo es el de José Sánchez Covisa quien fue designado por el Ministerio de la Educación Nacional (MEN) jefe de la cátedra de clínica dermatológica y sifilográfica de reciente creación, mientras que el resto de sus actividades las desarrollaba junto al reconocido bacteriólogo y parasitólogo alemán Martín Mayer en la sección de investigaciones dentro de la Dirección de Salubridad del Instituto Nacional de Higiene. Para este campo de investigación, aplicada a la situación sanitaria nacional, se consideró que el ministerio era el lugar apropiado para dar fuerza al estudio de las enfermedades tropicales, "protozoología médica, helmintología, dermatología y micología". Justamente estas dos últimas especialidades reunieron al micólogo venezolano Pablo Guerra y al dermatólogo español José Sánchez Covisa en investigaciones "sobre la acantosis, leishmaniasis, lepra y tuberculosis de la piel entre 1940 y 1944" (Guerra, 2003, p.720).

Pero sin duda la contratación que mayor impacto tuvo en la vida académica de la UCV fue la de Augusto Pi Sunyer. En el contrato que firmó en junio de 1939 con el Ministerio de Educación Nacional se indicaba que sus servicios "consistirán en investigaciones experimentales de fisiología patológica (cátedra libre de fisiopatología) y organización del Instituto de Medicina Experimental" (UCV, 1939). Sobre la biografía y la obra de Augusto Pi Suñer, nacido en Barcelona en 1879, existe un amplio número de referencias: libros de homenaje, monografías, estudios sobre su obra científica, sobre su labor intelectual o sobre su actuación pública. Lo primero a destacar es que llegó con una obra muy importante realizada como director del Instituto de Fisiología de la Universidad de Barcelona entre 1920 y 1938, de modo que la visión que tuvo Enrique Tejera al lograr su venida a Venezuela se situaba en el ámbito de la formación de investigadores y en el desarrollo de la infraestructura académica y administrativa adecuada. Cuando se incorporó a la cátedra de fisiología, se encontró con quienes serían sus dos primeros discípulos: Humberto García Arocha, jefe de los trabajos prácticos y Marcel Granier-Doyeux, preparador. Por su parte, Tejera consiguió en el Congreso Nacional una partida extraordinaria, adicional al presupuesto, para la adquisición de material científico e instrumental (Granier-Doyeux, 1962, p.1964-1968).

Desde entonces Pi Suñer comenzó a elaborar el ambicioso proyecto que habría de culminar en la fundación del Instituto de Medicina Experimental en 1940; contemporáneo 
con esta actividad colaboró en la reforma parcial del programa de estudios en la Facultad de Ciencias Médicas y en la conversión de la fisiología, la fisiopatología y la farmacología en ciencias experimentales; propuso la creación de la cátedra de bioquímica en sustitución de la de química médica; y la de fisiopatología en conexión con la de patología general reemplazándose, además, la cátedra de terapéutica general y materia médica por una moderna de farmacología. Uno de los autores que se ha ocupado de registrar la ciencia española en el exilio afirma, en cuanto a Pi Sunyer, que "es difícil evaluar relativamente qué fue más importante, si la escuela fisiológica catalana o la escuela experimental venezolana"; para forzar una equivalencia innecesaria, el autor eleva a 25 los años durante los cuales Pi Sunyer dirigió el Instituto de Medicina Experimental, cuando en realidad fueron 10, ya que en mayo de 1950 solicitó la jubilación por razones de salud: "fui afectado por un considerable accidente vascular cerebral", explicó (UCV, 1950a). Para evaluar la importancia de la inserción de Pi Sunyer en la universidad venezolana y su labor no es necesario torcer la calificación de su obra científica entre nosotros; el mismo autor afirma: "ya instalado en Caracas y decidido a arraigar en Venezuela, comienza por publicar artículos de difusión y puesta al día" (Giral, 1994, p.210-211). Permaneció en Venezuela hasta 1962, cuando se trasladó a México en donde falleció en 1965. Para no dejar 'desvalido' al instituto y atar su continuidad antes de jubilarse, realizó las diligencias necesarias para la contratación de su discípulo Rosendo Carrasco Forminguera, quien durante la primera etapa del exilio había permanecido en México en la cátedra de fisiología y en la de bioquímica de la Facultad de Medicina de la UCV. También propuso la contratación del fisiólogo argentino Bernard Houssay - Premio Nóbel de Medicina en 1948 - para la dirección del instituto. Sin embargo esta solicitud no fue atendida y Humberto García Arocha, su discípulo venezolano, fue su sucesor. Quedó así cerrada la transferencia.

Estas contrataciones y sus condiciones fueron objeto de debate en el Congreso en torno a la ley de educación aprobada en 1940. Un diputado - médico - proponía que la contratación de profesores extranjeros por parte del ejecutivo fuese "con carácter de asesores". Argumentaba sobre la existencia de "profesores nacionales de alta categoría científica que muy bien pueden desempeñar esos cargos" mientras "los extranjeros pueden ser asesores técnicos de los profesores nacionales"; para luego insistir, refiriéndose a las contrataciones de los médicos exiliados por parte del MSAS, que para ciertas materias sí era necesario recurrir a los profesores extranjeros:

\footnotetext{
Pongamos el caso de las Unidades Sanitarias: éstas se han venido a establecer ahora en Venezuela; si nosotros no tuviéramos un asesor extranjero, creo que las Unidades Sanitarias no podrían desempeñar un papel en forma. ... creo que los médicos venezolanos, que han estudiado en una Universidad como la nuestra ... muy bien pueden desempeñar muchas cátedras sin necesidad de asesores; pero hay otros, como el de Anatomía Patológica, etc. Materias bastante difíciles en nuestra Universidad, que necesitan de esos asesores, y que no se sentirían humillados por tener buenos asesores extranjeros, verdaderos sabios que vienen al país en estos momentos. (Venezuela, 1940)
}

La otra cuestión, igualmente debatida, fue si los profesores extranjeros contratados por el ejecutivo - y de libre remoción - podían actuar en las escuelas universitarias "aun sin haber revalidado". En este caso se agregó en la ley que los profesores extranjeros podrían 
actuar en las escuelas "cuando el ejecutivo federal los contrate exclusivamente para ese fin". De esta forma quedaría omitido el ejercicio profesional que estaba en el centro de la discusión sobre todo por parte de los médicos en función de diputados. Los argumentos apuntaban con toda claridad a este asunto:

El Despacho de Sanidad y Asistencia Social tiene bajo su dependencia y utiliza los servicios de profesionales eminentes; pero en el contrato que el Despacho firma con cada uno de estos individuos, queda establecido que durante su permanencia en el país, y a la orden del Ministerio, ninguno de estos individuos podrá ejercer su profesión. ... Se quiere que el profesor extranjero sea exclusivamente un profesor, y no que tenga probabilidad ninguna de entrar en el campo profesional y de ser una amenaza para los profesionales venezolanos. (Venezuela, 1940)

Los temas de estos debates se producían en 1940 en torno a la ley de educación, pero también los hubo, luego del golpe de estado del 18 de octubre de 1945, a propósito de la nueva constitución y del Estatuto Orgánico de Universidades Nacionales de 1946 y también con posterioridad al nuevo golpe de estado de 1948. En 1950, el Consejo Universitario de la UCV se vio en la necesidad de afrontar la cuestión sobre la escasez de médicos y la capacidad de graduarlos en el país ${ }^{16} \mathrm{y}$ de proponer un proyecto de reglamento de equivalencia de estudios, incorporaciones y reválida de títulos en consonancia con las nuevas circunstancias y su competencia en el otorgamiento de los títulos. El proyecto fue enviado a la Comisión Revisora de Legislación Sanitaria del Ministerio de Sanidad y Asistencia Social para obtener su opinión; en el informe de la Comisión, de la cual formaba parte el médico sanitarista exiliado Santiago Ruesta - de ahí su interés adicional -, se concluía que la importación de médicos extranjeros era una "necesidad que no puede ser atendida dentro del marco de una estricta legalidad sin la obtención de la reválida correspondiente", sobre todo porque en las disciplinas de carácter clínico y en especial las de carácter quirúrgico, los médicos no suelen aceptar trabajar en el interior "en virtud de la atracción que sobre ellos ejercen las grandes poblaciones para la conquista de una brillante clientela privada" y "prefieren gozar de la libertad que les proporciona el lucrativo ejercicio privado de su profesión". El informe tomaba una clara distancia desde el campo de la salud pública, amparado también en la Ley de Ejercicio de la Medicina, en la cual se establecía que los médicos extranjeros podían ejercer su profesión en docencia, investigación científica y salud pública, sin revalidar. Finalmente el informe argumentaba:

\footnotetext{
Si es cierto que se necesitan médicos, es preciso convenir que esa necesidad se deja sentir más hondamente en lo que se refiere a especialistas incondicionalmente disponibles que, aparte de cubrir las plazas no apetecidas por los médicos con título venezolano, permiten crear núcleos de especialización en el interior del país; y es por esta razón por la que nos mostramos partidarios de que sólo sea concedida la revalida a los médicos extranjeros que hayan cumplido satisfactoriamente dos años de ejercicio profesional en los lugares y posiciones que les señale el ejecutivo federal, teniendo en cuenta los antecedentes profesionales del candidato. (UCV, 1950b)
}

Sólo entonces se estaría en capacidad de juzgar ética y técnicamente, como indicaba el reglamento propuesto, al aspirante a revalidar su título que debería finalmente cumplir con el requisito de un examen integral "en el estudio de enfermos y en algún otro ejercicio práctico sobre Salud Pública" (UCV, 1950b). 
Hablaba con propiedad el Ministerio de Sanidad y Asistencia Social: entre 1936 y 1950 habían ingresado al país alrededor de 120 médicos españoles exiliados de los cuales más de la mitad fueron contratados por el Ministerio de Educación o el Ministerio de Sanidad y Asistencia Social, de estos últimos, 32 para las Medicaturas Rurales (Martín Frechilla, 2002).

\section{Los médicos exiliados en el dispositivo de salud pública ${ }^{17}$}

La estructura organizativa del Ministerio de Sanidad y Asistencia Social incluía tres vertientes operativas: la higiene ambiental y las enfermedades transmisibles - con las divisiones técnicas de ingeniería sanitaria, epidemiología y estadística vital, fiebre amarilla y peste, lepra, venereología, laboratorios, tuberculosis y malariología -; la administración sanitaria - con las unidades sanitarias, las medicaturas rurales, los hospitales, los centros de salud y las regiones sanitarias -; y la promoción de la salud - con las divisiones de educación sanitaria, higiene dental, oncología, farmacia, higiene mental, higiene escolar, materno infantil y servicio social. A esta trama se articuló un grupo de entes que progresivamente fueron adquiriendo autonomía - Escuela Nacional de Enfermeras, Instituto Nacional de Nutrición, Consejo Venezolano del Niño, Patronato de Comedores Escolares, Patronato Nacional de Ancianos e Inválidos etc. - la mayoría de ellos vinculados también a la promoción de la salud y la educación sanitaria.

El Instituto Nacional de Higiene - propuesto en el Programa de Febrero - fue creado en 1938 adscrito al Ministerio de Sanidad y Asistencia Social. Entre sus objetivos, además de realizar investigaciones sobre las enfermedades endemo-epidémicas y los métodos apropiados para combatirlas o de estudiar los problemas de nutrición, los análisis de aguas y de sustancias alimenticias, estaba la preparación técnica del personal para los distintos servicios del Ministerio: médicos, higienistas, inspectores de sanidad, preparadores de laboratorio, enfermeras sanitarias. Los objetivos educativos se afirmaban en los servicios de atención a la población, tanto en las medicaturas rurales dispersas en el interior del país como en las unidades sanitarias de atención integrada en el medio urbano. En ellas el médico, al igual que el maestro, enseñaba hábitos para la higiene personal y de la vivienda, para el tratamiento de alimentos, para la prevención de enfermedades o el contagio.

Los médicos exiliados de acuerdo con su formación y experiencia previa se insertaron en las vertientes señaladas; por una parte en la administración sanitaria: unidades sanitarias y medicaturas rurales, y por la otra, en cuanto a las enfermedades transmisibles, en las divisiones de tuberculosis, venereología y malariología. A riesgo de ser injusto en cuanto a la labor cumplida en cada una de estas dependencias, vamos a recorrer lo esencial de las inserciones de los médicos exiliados, en la seguridad de que algunos nombres y experticias quedarán afuera.

\section{Administración sanitaria}

Entre los más de treinta médicos exiliados que iniciaron su actividad en el país en las medicaturas rurales se destaca José María Bengoa Lecanda (Bilbao, 1913), quien fue contratado en 1937 para la medicatura rural de Sanare en el estado Lara; como otros de los 
médicos exiliados, su actividad no estuvo, los primeros años, enmarcada en lo que había sido su área de especialidad antes del exilio. Bengoa Lecanda, nutrólogo, publicó en 1940 uno de sus textos más conocidos: Medicina social en el medio rural venezolano sobre la experiencia en Sanare. Al crearse en 1942 una división de nutrición, adscrita a la Dirección de Salud Pública del MSAS, Bengoa Lecanda es llamado a Caracas. La división se convirtió primero en el Instituto Nacional Pro-Alimentación Popular, y luego, en 1949, en el Instituto Nacional de Nutrición. Bengoa Lecanda fue director técnico de ambos institutos acompañando en ellos al también médico exiliado José Ortega Durán (Ronda, 1905), adscrito primero a la División de Higiene Escolar, aunque sin abandonarla presidió, entre 1946 y 1948, el Instituto Nacional Pro-Alimentación Popular. En 1954, la Oficina Mundial de la Salud incluyó a José María Bengoa dentro de las listas de los Grupos de Expertos que en el campo de la nutrición actuaban como sus asesores. Ese mismo año quedó incorporado al personal directivo del organismo internacional en calidad de técnico designado por el Instituto Nacional de Nutrición.

En la División de Unidades Sanitarias encontraremos, desde los inicios, al mayor grupo de médicos exiliados: Antonio Ortiz de Landázuri (Madrid, 1893), Santiago Ruesta Marco (Zaragoza, 1899), Jesús Sahagún Torres (Ávila, 1892), José María Llopis Recio (Madrid, 1897), Guillermo Angulo Pastor (Bizkaia, 1895), José Pardo Gayoso, (La Coruña, 1902), Luis Bilbao Libano (Vizcaya, 1905), Alberto Mateo Alonso (Madrid, 1912) y José Solanes Vilapreño (Tarragona, 1909). Desde su llegada al país, a finales de 1937 o principios de 1938, Ortiz de Landázuri actuó como médico adjunto, encargándose primero de la Unidad Sanitaria del Este que cubría las necesidades del valle de Caracas, para luego trasladarse al extremo sur occidental del país e instalar la unidad sanitaria de la ciudad de San Cristóbal; al concluir su 'pasantía' en el interior fue llamado por el Instituto Nacional de Higiene como técnico bacteriólogo para finalmente asumir la dirección del Laboratorio de Epidemiología de la División de Epidemiología y Estadística Vital. Ruesta Marco llegó a Venezuela, contratado por el Ministerio de Sanidad y Asistencia Social entre finales de 1937 y principios de $1938 .{ }^{18}$ Desde su ingreso, Ruesta fue incorporado a la Dirección de Salud Pública como "asesor con funciones de asistencia técnica" y a cargo de los asuntos relacionados con la Sanidad Internacional, dada su ya reconocida y amplia carrera en ese ámbito. Primero instaló y dirigió la unidad sanitaria de la ciudad de Los Teques, para después realizar actividades similares en otras ciudades del centro-occidente del país. Su filosofía integralista y la defensa de las unidades sanitarias, como modelo de atención para el sistema nacional de salud pública, lo llevó también a impulsar, junto con otros médicos venezolanos, la creación en 1945 de las regiones sanitarias. Sahagún Torres llegó a Venezuela a mediados de 1939; fue encargado de la Unidad Sanitaria Modelo de Santa Teresa del Tuy, localidad próxima a Caracas, además de incorporarse como médico adjunto en la División Materno Infantil del MSAS en donde colaboró estrechamente con el eminente pediatra venezolano Pastor Oropeza, iniciador de la atención materno-infantil, de los estudios de pediatría y del desarrollo del conocimiento de la puericultura en Venezuela. Sahagún Torres fue profesor de la Escuela Nacional de Enfermeras y de la Escuela de Servicio Social, así como de los cursos de médicos higienistas. Su labor docente lo llevó, también, a dirigir la División de Educación Sanitaria del MSAS. En esta División se incorporaría, al 
final de los años cincuenta, el médico tisiólogo y educador sanitario, Llopis Recio, quien había llegado a Venezuela en 1949 para trabajar en la División de Unidades Sanitarias. Angulo Pastor, médico pediatra, fue contratado a mediados de 1939 para el Instituto Nacional de Puericultura en donde cumplió una amplia labor como educador. Al mismo instituto llegó en 1939 el también médico pediatra Pardo Ganoso. Cuando en 1938 se creó la División de Unidades Sanitarias, se organizó allí una sección especial que incorporaba a todos los laboratorios del país que, en 1941, se convertiría en División de Laboratorios. Para esa división fue contratado ese mismo año como técnico viajero de laboratorios Bilbao Libano, quien en 1946 al asumir el Instituto Nacional de Higiene, su autonomía del MSAS, fue nombrado médico adjunto de la División de Laboratorios y luego director. Si bien Mateo Alonso - médico psiquiatra y especialista en higiene mental - llegó a Venezuela a principios de 1940 contratado como médico rural, en 1944, Ortega Durán llamó a su colega exiliado a Caracas para que se encargase bajo sus órdenes de la Colonia Psiquiátrica de Anare, cercana a la capital. Luego de que Mateo Alonso fuese incorporado a la División de Higiene Mental, el MSAS contrató en 1949 para la colonia a Solanes Vilapreño, médico psiquiatra que en 1952 pasó a dirigir una nueva y moderna colonia psiquiátrica en el centro del país. La abundante producción científica de Solanes Vilapreño, publicada en revistas especializadas venezolanas y europeas, culminó en 1993, un año antes de su muerte, con la edición de un libro que recoge, en una profunda reflexión, el impacto psicológico del exilio y la emigración.

Si asumimos la paridad entre maestro y médico rural o médico adjunto en una modestísima medicatura rural o en las unidades sanitarias de las pequeñas ciudades del interior del país, la labor educativa en el campo de la salud y la higiene de médicos exilados luce inestimable.

\section{Enfermedades contagiosas}

En algunos casos en los que la experiencia previa y la especialización de los médicos exiliados lo permitió, la inserción fue fructífera. Entre ellos destacan: Leoncio Jaso-Roldán (Vigo, 1903), José Sánchez Covisa (Cuenca, 1881), Ángel Díaz Vázquez (Ribadeo, 1912), Antonio Gómez Marcano (Cádiz, 1905), Miguel Nieto Caicedo (Almería, 1909) y Carlos Zozaya (Madrid, 1897). Desde su llegada a Venezuela, a finales de 1939, Jaso-Roldán trabajó en la División de Tuberculosis, en el Dispensario Antituberculoso de Caracas y en los servicios sociales del Ministerio de Obras Públicas. Cuando en 1947 fue creado el Instituto Nacional de Tuberculosis, adscrito al MSAS, Jaso-Roldán se incorporó como médico jefe de la sección de cardiología del Departamento de Fisiopatología del sanatorio. En estos centros de atención desarrolló una importante labor educativa a la cual se sumó la publicación de varios trabajos en las revistas especializadas venezolanas, uno de ellos junto José Sánchez Covisa, catedrático titular de dermatología y sifilografía en la Universidad de Madrid. Sánchez Covisa llegó a Venezuela a mediados de 1939 contratado para la División de Venereología en la cual trabajó hasta su muerte en 1944, compartiendo sus actividades como ya señalamos - tanto en la docencia de la cátedra de clínica dermatológica y sifilográfica de la UCV y el primer curso de médicos higienistas como en investigación en la Dirección de Salubridad del Instituto Nacional de Higiene. 
La inserción de los médicos exiliados en las actividades de la División de Malariología y la Escuela de Expertos Malariólogos, ambas instituciones adscritas al MSAS, fue relevante desde la perspectiva de sus actuaciones particulares, potenciada por el éxito de la política nacional emprendida en 1936 a partir de la Ley de Defensa contra el Paludismo. Arnoldo Gabaldón (Trujillo, 1909) fue el primer director de la División de Malariología y su adjunto, Alberto Fernández (Caracas, 1892), se encargaría de la Escuela de Expertos Malariólogos hasta su muerte en 1938, cuando Gabaldón asumió los dos cargos. Gabaldón había sido ayudante entre 1928 y 1930 de Tejera en el Laboratorio de Bacteriología y Parasitología de la Dirección de Sanidad Nacional; en 1931 obtuvo su doctorado en Medicina en la UCV y viajó al Instituto de Enfermedades Navales y Tropicales de Hamburgo; en 1932 regresó a Venezuela, luego de visitar la Estación Experimental para la Lucha Antimalaria de Roma, auspiciada por la Fundación Rockefeller; en 1933 se inscribió en la Escuela de Higiene y Salud Pública de la Universidad de Johns Hopkins, obteniendo en 1935 el doctorado en Ciencias de la Higiene. Antes de regresar a Venezuela realizó una breve pasantía en el laboratorio de la Fundación Rockefeller de Nueva York especializado en el estudio de la malaria. Las vertientes que confluyeron en el modelo organizativo de la División de Malariología fueron múltiples, según el propio Gabaldón explicó en 1943 en el discurso que pronunció en la inauguración del edificio de la División de Malariología en la ciudad de Maracay, en el centro del país. Tuvieron influencia importante, según dijo, sus estudios en el exterior y los de sus colaboradores, el intercambio de experiencias con los funcionarios de la Fundación Rockefeller y en especial la organización de la Estación Experimental para la Lucha Antimalaria de Roma que promovía y combinaba "la enseñanza e investigación del paludismo" (Gutiérrez, 1998, p.28-33).

La Escuela de Higiene y Salud Pública, que inició sus actividades con el adiestramiento del personal del MSAS, comenzó en 1944 a dictar anualmente unos cursos internacionales de malaria a los cuales asistieron becarios de instituciones nacionales y extranjeras. Como responsables de distintas asignaturas nos encontramos a lo largo de los años a cuatro médicos exiliados españoles que llegaron entre mediados de 1939 y 1941 contratados para la División de Malariología.

Díaz Vázquez tuvo diversas responsabilidades en las zonas en las que se dividió el país dentro de la campaña de erradicación de la malaria; fue profesor de los cursos internacionales sobre malaria y, a mediados de los años cincuenta, desplazó su interés hacia la enfermedad de Chagas sobre la cual desarrolló varios proyectos de investigación en el Instituto de Medicina Tropical de la UCV. Gómez Marcano recorrió, al igual que Nieto Caicedo, como médico de campo las distintas zonas para la erradicación de la malaria. En la segunda etapa de los cursos de médicos higienistas, Gómez Marcano fue profesor, junto con Gabaldón y Zozaya, de la asignatura Estudios del control de los vectores de las enfermedades metaxénicas y en solitario dictó la asignatura Anatomía patológica de la malaria. Cuando en 1950, Arnoldo Gabaldón pasó a dirigir la campaña contra la fiebre aftosa, Gómez Marcano se encargó, además, de la coordinación de los cursos internacionales. Un malariólogo venezolano, que fue su discípulo, relata que "jugó un papel fundamental en la orientación de la división", tanto en docencia como en el fomento de la investigación, así como en el éxito de "los planes logísticos de la campaña con DDT", iniciada en 1945 para la erradicación de la enfermedad (López Ramírez 1987, p.199-202). 
Por su parte, Nieto Caicedo ${ }^{19}$ estuvo destinado como médico de campo hasta 1948, año en el cual pasó a la sede central de la División de Malariología en Maracay. Cuando en 1955, el gobierno de Venezuela y la Oficina Sanitaria Panamericana suscribieron, luego del exitoso programa de erradicación de la malaria, un acuerdo de cooperación para toda América Latina, Nieto Caicedo fue cedido por Venezuela como experto en la materia para iniciar un programa similar en Colombia. Participó, sin embargo, en los cursos internacionales sobre malaria como profesor de una asignatura que presentaba, desde la actividad epidemiológica práctica, un modelo de organización de las zonas para la erradicación de la enfermedad.

De los tres médicos exiliados contratados por la División de Malariología, Zozaya fue sin duda el que mayor experiencia acumulada tenía como malariólogo e investigador de la enfermedad antes de partir para el exilio a Colombia. Cuando fue contratado en 1948 incorporó toda su experiencia a la División de Malariología, participando, además, en los cursos internacionales de malaria como profesor de parasitología y bacteriología, así como, en la segunda etapa de los cursos de médicos higienistas.

El éxito de la campaña antimalárica, cuyo impacto político y social fue contundente, afectó tanto a la organización de la División como a la Escuela para la formación de especialistas, pero sobre todo a la investigación sobre malaria. Ana Teresa Gutiérrez, en su excelente monografía, solidamente documentada a partir del archivo personal de Arnoldo Gabaldón, afirma que "al vincularse estrechamente la División con el desarrollo del programa de erradicación se atrofió la investigación en ella. Una organización tan pragmática no atraía a profesionales interesados en investigar sobre el paludismo, por el contrario, huían de la rutina de evaluar la evolución de las fumigaciones en todo el país". El propio Gabaldón afirma - "no estaba satisfecho con los logros alcanzados en la consolidación de la investigación sobre malaria en el país que seguía considerando como 'la pata coja' de su proyecto" (Gutiérrez, 1998, p.101-118). A ello contribuyó, sin duda, la constatación de los efectos perversos de los insecticidas residuales con los cuales se fumigaban las viviendas rurales contra el aumento de los chipos, insecto vector en la cadena de trasmisión de la enfermedad de Chagas.

\section{Para concluir}

En junio 1939 llegó a Caracas una comisión social ${ }^{20}$, solicitada por el gobierno de Venezuela al de los Estados Unidos, que trabajó durante tres meses apoyada por una comisión venezolana designada para tal efecto a fin de evaluar y jerarquizar los problemas del país. En el rubro 'salubridad e higiene' del informe entregado a la presidencia de la república, encontramos frases como estas:

las autoridades venezolanas son merecedoras del más alto encomio por la atención y esmero que han prestado a los problemas de salubridad y sus soluciones... Venezuela ha alcanzado, en los últimos dos o tres años, avances que probablemente no han sido superados ni igualados por ningún otro país del mundo... la comisión se limita a expresar sinceramente su admiración. (CSSN, 1939)

Y eso que la exitosa campaña para la erradicación de la malaria no había comenzado. En 1949, el Ministerio de Sanidad y Asistencia Social creó una comisión ad hoc ${ }^{21}$ para 
revisar el conjunto de la estructura sanitaria del país, y en particular la organización del propio ministerio cuyo crecimiento quedaba reflejado en un presupuesto nueve veces mayor al de su creación en 1936. El informe, presentado y archivado en 1952, apoyaba la "integración de servicios preventivos y curativos" a la vez que recomendaba una reorganización funcional del MSAS por medio de la definición y ubicación precisa "de las funciones directivas y asesoras, las funciones ejecutivas y las funciones auxiliares". Proponía también "la descentralización administrativa del Ministerio"; recomendaba "la extensión del trabajo sanitario preventivo a la población rural"; reclamaba la necesidad de aumentar el personal calificado "en las disciplinas sanitarias, especialmente en los campos de la enfermería y el saneamiento"; reconocía la necesidad de disponer de información "sobre las características ecológicas y sociales y las tendencias evolutivas de la población". El informe, de casi 300 páginas, incluía una carta de Gabaldón a Hill y otra de Ruesta a Gabaldón a propósito de la primera. Además de los asuntos técnicos y organizativos encontrados, no en torno a la sanidad sino a la asistencia social, uno y otro concuerda en que "el porvenir de nuestra sanidad, una vez superada la etapa del saneamiento, es el control de nuestra población", según Ruesta. Mientras Gabaldón señala que "la mejora de nuestro índice vital, mayormente apreciada en las antiguas zonas rurales afectadas por la malaria, traerá un aumento no balanceado de nuestra población" cuya mayor velocidad de crecimiento presionará las migraciones internas. Para momento en que Ruesta y Gabaldón escribieron estas cartas estaban por publicarse los alarmantes datos de crecimiento del censo de población de $1950^{22}$, resultados acompañados de una vertiginosa movilidad espacial de la población y de la inversión de la relación entre la población urbana y rural a favor de la primera (Venezuela, 1971, p.28-33).

Se ha reunido para concluir a Ruesta y a Gabaldón como cabezas visibles del dispositivo venezolano de salud pública durante la primera mitad del siglo XX. Ambos empujaron un sólido proceso de transferencia y modernización del país; solo el exilio del médico español marca la diferencia.

\section{NOTAS}

${ }^{1}$ Resolución de 31 de julio de 1889 disponiendo que por cuenta del gobierno nacional se traslade a París un joven médico, de nacionalidad venezolana, graduado de doctor en la Universidad Central, de buena conducta y de aptitudes reconocidas, a fin de que curse allí teórica y prácticamente las especialidades que se expresan.

${ }^{2}$ El Hospital Vargas fue creado en 1888 con vocación de hospital clínico universitario con una dotación de "por lo menos mil camas, debiendo tener una construcción análoga y régimen semejante al del Hospital Lariboissière establecido en París" (Vargas Arenas, 1991, p.44).

${ }^{3}$ Siguieron los gobiernos de Eleazar López Contreras (1935-1941), Isaías Medina Angarita (1941-1945) y Marcos Pérez Jiménez (como miembro de un triunvirato (1948-1952) y en solitario (1952-1958). Así entre 1899 y 1958, gobernaron Venezuela generales andinos, salvo durante el trienio (1945-1948) el partido Acción Democrática (AD) con los socialdemócratas Rómulo Betancourt (1945-1947) y Rómulo Gallegos (1948). En 1945, los militares descontentos con el estamento gomecista, acompañados de los civiles de AD inauguraron los golpes de estado del siglo XX. Después los militares retomaron en solitario el poder en 1948 para nuevamente reunidos, civiles y militares - otros evidentemente -, reinstalasen en 1958 y para el resto del siglo una era de gobiernos civiles electos. 
${ }^{4}$ Distrito Federal era, entonces, una entidad jurídico-administrativa que albergaba territorialmente a la capital y sus alrededores, incluyendo el puerto de La Guaira.

${ }^{5}$ En México en 1902, luego de la $2^{\text {a }}$ Conferencia, se dio forma a la Oficina Internacional de las Repúblicas Americanas. En la $4^{a}$ Conferencia, celebrada en Buenos Aires en 1910, la asociación y el organismo se denominarían Unión de las Repúblicas Americanas y Unión Panamericana. La legislación sanitaria y los organismos encargados de aplicarla aparecen en Venezuela claramente concertados en su estructura, competencias y normas con las decisiones continentales, especialmente luego de la Conferencia de Buenos Aires (Seara Vázquez, 1974).

${ }^{6}$ En esta Conferencia, Cuba, aún colonia, estuvo presente con un delegado de excepción dentro de la representación española, Carlos J. Finlay (1833-1915). El científico cubano expuso en esta conferencia el 18 de febrero de 1881 - las bases de su doctrina metaxénica sobre el contagio de las enfermedades y el mosquito como agente de transmisión de la fiebre amarilla (Finlay et al., 1880-1881).

${ }^{7}$ Por otra parte, desde 1893 comenzaron a reunirse los Congresos Panamericanos de Medicina.

${ }^{8}$ El primer Código Sanitario Panamericano fue aprobado en la II Convención Sanitaria Internacional de las Republicas Americanas de 1905.

${ }^{9}$ El texto de la ponencia y las recomendaciones fueron publicadas en la Gaceta Médica de Caracas, n.418, 1912 (López Ramírez, 1987, p.35).

${ }^{10}$ Rafael Rangel (1877-1909), investigador de las enfermedades tropicales y pionero de los estudios de parasitología.

${ }^{11}$ En apoyo a su afirmación, Vessuri cita un texto mimeografiado de 1993 que no ha sido posible consultar: Julia Rodríguez, The failure of public health philanthropy: the Rockefeller Foundation in Venezuela, 1926-1934. Solo una visita a los archivos de la Fundación (http://archive.rockefeller.edu) permitiría adentrarse en las razones del cese temporal de la cooperación y avanzar algunas hipótesis. En los textos ya clásicos de Marcos Cueto, el mejor estudioso de la Fundación en su relación con América Latina, no hemos encontrado referencias al respecto. De la muy abundante bibliografía sobre la Fundación nos hemos limitado a citar el texto de Vessuri por ser el único que conocemos que vincula a la Fundación con el exilio republicano en Venezuela.

12 En 1902, siendo Gómez vicepresidente, Venezuela sufrió un bloqueo de Gran Bretaña y Alemania por el impago de la deuda externa; la invasión no se produjo por la mediación norteamericana. Entre 1911 y 1934 los Estados Unidos ocuparon, intervinieron y derrocaron directamente o indirectamente, cuatro veces a Nicaragua, dos a Cuba, dos a México y una a Haití, Panamá y República Dominicana.

${ }^{13}$ Médico higienista, sus vínculos con la Fundación Rockfeller, mientras ejerció el cargo de Director General de Sanidad, dieron como resultado su exilio a Estados Unidos en donde sería profesor de bioestadística y epidemiología en la Universidad de Johns Hopkins de Baltimore.

${ }^{14}$ El Programa de Febrero fue criticado en su momento por ser "un programa blanco para una democracia mulata". El Programa reunía un ideario modernizador basado en una reforma legal, un programa de higiene pública y asistencia social, la construcción de vías de comunicación, la organización de la educación nacional, el fomento de la agricultura y la cría, el establecimiento de una política fiscal y comercial, una política de inmigración y colonización (López Contreras, 1966, p.16-30).

15 Así denomina la historiografía venezolana al período de gobierno de Juan Vicente Gómez entre 1908 y 1918. Durante ese período un grupo de intelectuales positivistas ejerció responsabilidades en la administración pública y en el poder legislativo, para luego refugiarse a modo de exilio en el servicio diplomático.

${ }^{16}$ Un informe del MSAS cuantificaba en cuatro mil los médicos que necesitaba el país; mientras las cifras indicaban que solo había dos mil, de los cuales unos trescientos poseían títulos extranjeros "los más de ellos ejercen sus actividades profesionales al servicio del Ministerio de Sanidad y Asistencia Social", decía el informe.

17 La información para esta sección proviene de Archila, 1956; Bengoa Lecanda, 1982; Giral, 1994; Gutiérrez, 1998; Guerra, 2003; Martín Frechilla, 1998, 2001, 2002, 2006; Venezuela, 1936-1958.

18 Según la información suministrada por la familia de Santiago Ruesta a Encarna Gascón Pérez de la Universitat de Alacant, su llegada a Venezuela fue en 1939; fecha que contradice a Ricardo Archila y a los documentos oficiales.

${ }^{19}$ Gabaldón intervino directamente en dos contrataciones: en la de Nieto Caicedo cuando descubrió en los currículos que tenía el Instituto de Inmigración y Colonización que había realizado un curso de 
medicina tropical y parasitología; y en la de Zozaya en plena campaña de erradicación de la malaria en 1948. Hay algo de novela en la afirmación de Francisco Guerra de que fue Gabaldón "quien sacó de los campos de concentración franceses y del exilio interior de España a los médicos republicanos y los supo utilizar situándolos en unidades sanitarias rurales, evitando su residencia en los grandes núcleos urbanos" (Guerra 2003, p.717-751).

${ }^{20}$ Estuvo compuesta por veinte miembros y presidida por el reverendo James M. Drought. En ella estaban representadas varias universidades norteamericanas - Notre Dame, Columbia Fordham - y diversas organizaciones con especialistas por áreas - trabajo, educación, vivienda, organización social, salubridad pública -, que a su vez eran funcionarios (CSSN, 1939).

${ }^{21}$ La comisión, que presentó su informe en 1952 estuvo integrada por cuatro funcionarios del MSAS Demetrio Castillo, L. García Maldonado, J. A. Jove y Daniel Orellana -; un funcionario de los servicios de salud pública de Puerto Rico y otro del de Estados Unidos; dos profesores de la Escuela de Medicina de Puerto Rico y de la Universidad de Columbia; y Rolla B. Hill por la Fundación Rockefeller (Venezuela, 1971).

22 En el censo de 1936 la población era 3,3 millones, 3,8 en 1941, 5 en 1950, 7,5 en 1961; comenzamos el siglo XX con $80 \%$ de población rural y $20 \%$ de población urbana y lo terminamos en la relación invertida.

\section{REFERENCIAS}

ARCHILA, Ricardo.

Historia de la sanidad en Venezuela. Caracas: Imprenta Nacional. 1956.

ARCHILA, Ricardo.

Luís Razetti o biografía de la superación. Caracas: Imprenta Nacional. 1952.

BENGOA LECANDA, José María.

Médicos vascos exiliados en Venezuela. Trabajo presentado en la Primera Reunión

Internacional de Médicos Vascos, 4-11 sep.

1982. San Sebastián. 1982.

BERNABEU-MESTRE, Josep.

La utopía reformadora de la Segunda

República: la labor de Marcelino Pascua al frente de la Dirección General de Sanidad, 1931-1933. Revista Española de Salud Pública, [Madrid], n.74, p.1-13. 2000.

Congreso...

Congreso Venezolano de Municipalidades, 1: actas y conclusiones (1913). Caracas: Congreso Nacional. (Pensamiento Político Venezolano del Siglo XX, t.4, n.9). 1983.

CSSN.

Comisión de Servicio Social Norteamericano.

Economía social: Venezuela. Caracas: MSAS. 1939.

\section{DISTRITO FEDERAL.}

Gaceta Municipal del Distrito Federal. [Caracas], n.1000, 26 mayo 1910; n.1001, 28 mayo, 1910; n.1005, 7 jun. 1910; n.1006, 9 jun. 1910, n.1007, 11 jun. 1910; n.1008, 14 jun. 1910; n.1009, 16 jun. 1910; n.1010, 18 jun. 1910; n.1012, 23 jun. 1910; n.1016 2 jul. 1910.
FINLAY, Carlos J. et al.

Extracto de las deliberaciones de la Conferencia Sanitaria Internacional de Washington. Anales de Real Academia de Ciencias Médicas, Físicas y Naturales de La Habana. Revista Científica, [La Habana], t.17, p.449-495. 1880-1881.

GARCÍA, Juan César.

Crecimiento y transformación de la medicina estatal. Revista Latinoamericana de Salud, s.l., n.1, p.102-117. 1981.

GIRAL, Francisco.

Ciencia española en el exilio (1939-1989).

Barcelona: Editorial Anthropos. 1994.

GRANIER-DOYEUX, Marcel.

La obra de Augusto Pi Suñer en Venezuela. Acta Científica Venezolana, [Caracas], v.13, n.5, p.164-168. 1962.

GUERRA, Francisco.

La medicina en el exilio republicano. Madrid: Universidad de Alcalá. 2003.

GUITERAS, Juan.

Informe sobre la fiebre amarilla en Venezuela. Gaceta Médica de Caracas, Caracas, n.24, p.231241. 1917.

GUTIÉRREZ, Ana Teresa.

Tiempos de guerra y paz: Arnoldo Gabaldón y la investigación sobre malaria en Venezuela (19361990). Caracas: Cendes/UCV. 1998.

HILL, Rolla; BENARROCH, Elías.

Anquilostomiasis y paludismo en Venezuela. Caracas: Editorial Elite. 1940. 
LEAL, Ildefonso.

Historia de la UCV. Caracas: Ediciones del Rectorado. 1981.

LÓPEZ CONTRERAS, Eleazar.

Gobierno y administración, 1936-1941. Caracas: Editorial Arte. 1966.

LÓPEZ RAMÍREZ, Tulio.

Historia de la Escuela de Malariología y Saneamiento Ambiental de Venezuela. Caracas: MSAS. 1987.

MARTÍN-FRECHILLA, Juan José.

Forja y crisol: la Universidad Central, Venezuela y los exiliados de la Guerra Civil española, 1936-1958. Caracas: Consejo de Desarrollo Científico y Humanístico de la Universidad Central de Venezuela. 2006.

MARTÍN-FRECHILLA, Juan José.

Ni bendito ni maldito: visión de conjunto del impacto del petróleo en la sociedad venezolana. In: Martín Frechilla, Juan José; Texera Arnal, Yolanda (Comp.). Petróleo nuestro y ajeno (la ilusión de modernidad). Caracas: Consejo de Desarrollo Científico y Humanístico de la Universidad Central de Venezuela. p.23-60, 2005.

MARTÍN-FRECHILLA, Juan José.

El difícil camino de la salud pública: los médicos españoles exiliados en Venezuela, 1936-1950. Montalbán, [Caracas], n.36, p.221-250. 2002.

MARTÍN-FRECHILLA, Juan José. De diplomático republicano a arquitecto exiliado: Fernando Salvador en Venezuela. Cuadernos Republicanos, [Madrid], n.44, p.79-97. 2001.

MARTÍN-FRECHILLA, Juan José.

Los olvidados: Fernando Salvador y la arquitectura sanitaria en Venezuela. Tecnología y Construcción, [Caracas], n.14, v.1, p.21-34. 1998.

OCHOA MOLINA, Rigel.

La campaña pro letrinas y su alcance sanitario durante la Venezuela gomecista. Ensayos Históricos, Caracas, v.1, n.1, p.123-142.

Disponible en: http://www.revele.com.ve/ revistas.php?rev=ensayos_historicos. 2002.

RAZETTI, Luis.

Obras completas. t. 2. Caracas: Ministerio de Sanidad y Asistencia Social. 1962.

RAZETTI, Luis.

Saneamiento de la ciudad de Caracas. Caracas: Primer Congreso Venezolano de Medicina. 1911.

RECOPILACIÓN...

Recopilación de leyes y decretos de Venezuela. t.15. Caracas: s.n. 1891.

\section{RESOLUCIONES...}

Resoluciones del Primer Congreso Venezolano de Medicina. Boletín de la Unión Panamericana, Washington, p.301. ago. 1911.

RODRÍGUEZ LEMOINE, Vidal.

Los inicios de la investigación biomédica en Venezuela: el Instituto Pasteur de Caracas (1895-1902). In: Martín Frechilla, Juan José; Texera Arnal, Yolanda (Comp.). Modelos para desarmar: instituciones y disciplinas para una historia de la ciencia y la tecnología en Venezuela. Caracas: Consejo de Desarrollo Científico y Humanístico, UCV. p.219-255. 1999.

RODRÍGUEZ LEMOINE, Vidal.

Del Instituto Pasteur de Caracas (1895) al Instituto Nacional de Higiene (1938). Boletín de la Sociedad Venezolana de Microbiología, Caracas, n.16, v.1, p.25-31. 1996.

RODRÍGUEZ OCAÑA, Esteban; BERNABEUMESTRE, Joseph; BARONA VILAR, Josep Lluís. La Fundación Rockefeller y España, 1914-1939: un acuerdo para la modernización científica y sanitaria. In: García Hourcade, J.L.; Moreno Yuste, J.M.; Ruiz Hernández, G. (Coord.). Estudios de historia de las técnicas, la arqueología industrial y las ciencias II: VI Congreso de la Sociedad Española de Historia de las Ciencias y de las Técnicas, Segovia-La Granja, 9-13 sep. 1996. Salamanca: Junta de Castilla y León. p.531-539. 1998.

SAVILLE, Thorndike.

El abastecimiento de agua en Venezuela. Revista de Técnica del Ministerio de Obras Públicas, Caracas, n. 55, p.7-29. 1933.

SEARA VÁZQUEZ, Manuel.

Tratado general de la organización internacional. México: Fondo de Cultura Económica. 1974.

UCV.

Universidad Central de Venezuela. Archivo del Consejo Universitario. CU 5. 1950a.

UCV.

Universidad Central de Venezuela. Archivo del Consejo Universitario. CU 10. 1950b.

UCV.

Universidad Central de Venezuela. Archivo del Consejo Universitario. CU 2. 1939.

VARGAS ARENAS, Rafael E. Hospital Vargas (1891-1991): influencia en la medicina nacional. Caracas: s.n. 1991.

VENEZUELA.

Ministerio de Sanidad y Asistencia Social. Estudio de la Organización del Ministerio de Sanidad y Asistencia Social de Venezuela: informe presentado en 1952. Caracas: MSAS. 1971. 
VENEZUELA.

Congreso Nacional. Diario de Debates, [Caracas], n. 52. 1940.

\section{VENEZUELA.}

Ministerio de Sanidad y Asistencia Social. Memoria, Caracas. 1936-1958.

VESSURI, Hebe.

Enfermería de salud pública, modernización y cooperación internacional: el proyecto de la Escuela Nacional de Enfermeras, 1936-1950. In: Martín Frechilla, Juan José; Texera Arnal,
Yolanda (Comp.). Modelos para desarmar: instituciones y disciplinas para una historia de la ciencia y la tecnología en Venezuela. Caracas: Consejo de Desarrollo Científico y Humanístico de la Universidad Central de Venezuela. p.319-359. 1999.

VILLANUEVA, Laureano.

Las ciencias médicas en Venezuela. In: Primer libro venezolano de literatura, ciencias y bellas artes. Caracas: El Cojo Ilustrado. p.CCXIIICCXXX. 1895. 